\title{
Applications of In Vivo Imaging in the Evaluation of the Pathophysiology of Viral and Bacterial Infections and in Development of Countermeasures to BSL3/4 Pathogens
}

\author{
Thomas M. Bocan, ${ }^{1,2}$ Rekha G. Panchal, ${ }^{1}$ Sina Bavari ${ }^{1}$ \\ ${ }^{1}$ Molecular and Translational Sciences, US Army Medical Research Institute of Infectious Diseases (USAMRIID), 1425 Porter Street, \\ Ft. Detrick, MD, 21702, USA \\ ${ }^{2}$ The Geneva Foundation, 917 Pacific Ave, Suite 600, Tacoma, WA, 98402, USA
}

\begin{abstract}
While preclinical and clinical imaging have been applied to drug discovery/development and characterization of disease pathology, few examples exist where imaging has been used to evaluate infectious agents or countermeasures to biosafety level (BSL)3/4 threat agents. Viruses engineered with reporter constructs, i.e., enzymes and receptors, which are amenable to detection by positron emission tomography (PET), single photon emission tomography (SPECT), or magnetic resonance imaging (MRI) have been used to evaluate the biodistribution of viruses containing specific therapeutic or gene transfer payloads. Bioluminescence and nuclear approaches involving engineered reporters, direct labeling of bacteria with radiotracers, or tracking bacteria through their constitutively expressed thymidine kinase have been utilized to characterize viral and bacterial pathogens post-infection. Most PET, SPECT, CT, or MRI approaches have focused on evaluating host responses to the pathogens such as inflammation, brain neurochemistry, and structural changes and on assessing the biodistribution of radiolabeled drugs. Imaging has the potential when applied preclinically to the development of countermeasures against BSL3/4 threat agents to address the following: (1) presence, biodistribution, and time course of infection in the presence or absence of drug; (2) binding of the therapeutic to the target; and (3) expression of a pharmacologic effect either related to drug mechanism, efficacy, or safety. Preclinical imaging could potentially provide real-time dynamic tools to characterize the pathogen and animal model and for developing countermeasures under the U.S. FDA Animal Rule provision with high confidence of success and clinical benefit.
\end{abstract}

Key words: In vivo imaging, MRI, PET, SPECT, CT, Optical, Ultrasound, BSL3/4 pathogens Abbreviations: $\left[{ }^{18} \mathrm{~F}\right] \mathrm{FDG}, 2$-Deoxy-2- $\left[{ }^{18} \mathrm{~F}\right]$ fluoro-D-glucose; $\left[{ }^{18} \mathrm{~F}\right] \mathrm{FLT},\left[{ }^{18} \mathrm{~F}\right]$ fluoro-3-dexoythymidine; $\left[{ }^{18} \mathrm{~F}\right] \mathrm{PF}-05270430,4-\left(3-\left[{ }^{18} \mathrm{~F}\right]\right.$ fluoroazetidin-1-yl)-7-methyl-5-\{1-methyl-5-[4-(trifluoromethyl)phenyl]1H-pyrazol-4-yl\}imidazo[5,1-f]-[1,2,4]triazine; $\left[{ }^{124,125} /{ }^{18} \mathrm{~F}\right] \mathrm{FIAU},\left[{ }^{124,125} / /{ }^{18} \mathrm{~F}\right]-29-$-fluoro-29-deoxy-1b-D-arabinofuranosyl-5-iodouracil; BSL, Biosafety level; CHIKV, Chikungunya virus; CT, Computed tomography; EEEV, Eastern equine encephalitis virus; MRI, Magnetic resonance imaging; MRS, Magnetic resonance spectroscopy; PET, Positron emission tomography; RRV, Ross River virus; SINV, Sindbis virus; SPECT, Single photon emission tomography; US, Ultrasound; VEEV, Venezuelan equine encephalitis virus; WEEV, Western equine encephalitis virus 


\section{Introduction}

$\mathrm{P}$ reclinical and clinical in vivo imaging approaches have

been widely utilized in the characterization of disease and drug efficacy across numerous therapeutic areas, most notably, neuroscience, oncology, cardiovascular, and immunology. Few examples exist where in vivo imaging has been applied to the evaluation of infectious agents, anti-infective drug discovery, and/or biosafety level (BSL)3/4 biothreat agents. There are very likely several practical reasons for the limited use of in vivo imaging in the assessment of BSL3/4 infectious agents such as the need for significant biocontainment facilities of which there are few where imaging capabilities exist, isolation of imaging hardware from infected animals, and the rapid onset of the disease in infected animals. Attempts to image animals infected with BSL3 agents have employed self-contained isolation chambers, i.e., sealed tubes $[1,2]$ to avoid contamination. Some groups have installed imaging systems within a BSL2 environment to allow for easier hardware maintenance or utilized large Philips Bioshield ${ }^{\mathrm{TM}}$ polycarbonate plastic tubes extending from the BSL4 containment space into the bores of the various scanners to isolate the hardware from the infectious agents [3]. Others have installed the imaging equipment directly into BSL3 containment and developed procedures for infected animal isolation and hardware decontamination, e.g., gaseous paraformaldehyde or hydrogen peroxide. All of the above approaches come with various disadvantages such as the requirement for modified imaging hardware to accommodate the containment barriers, reduced image resolution, scatter and attenuation, reduced flexibility or higher cost of operation with regard to using disposable components, e.g., magnetic resonance imaging (MRI) surface coils, and the potential exists for a reduced hardware lifespan due to exposure to caustic decontamination solvents. Animal isolation approaches and imaging outside of containment limit the breadth of pathogens that could be utilized due to safety concerns related to isolation chamber malfunction, security risks associated with taking infected animals outside containment, and risks of exposure due to personnel errors.

Despite the challenges, in vivo imaging could play a significant role in better understanding the pathophysiology of infectious agents and in the discovery and development of therapies for BSL3/4 pathogens. Given the nature of the pathogens and despite the absence of drugs to treat the infections, classical methods of drug development cannot be applied. The development pathway for anti-viral and antibacterial products against viral and bacterial threat agents is complex because clinical efficacy studies may not be feasible or ethical. In these instances, the U.S. FDA Animal Rule allows animal efficacy data to be used along with human safety evaluation data and pharmacokinetic information to support drug approval [4]. Under the Animal Rule, a thorough understanding of the pathophysiology of the agent in the animal is needed so as to qualify that the model used for drug efficacy assessment and for linkage to phase I human pharmacokinetic/pharmacodynamic parameters is representative of the human condition.

In vivo imaging is well suited to provide a dynamic assessment of pathogen infection, disease progression, and resolution following drug intervention. The in vivo imaging tools are non-invasive except when using contrast agents, e.g., MRI, computed tomography (CT), and ultrasound (US), or semi-invasive, e.g., positron emission tomography (PET), single photon emission computed tomography (SPECT), and optical, and when used together can serially monitor both structural and functional changes associated with disease progression. In this article, we will review (1) our basic understanding of viral and bacterial infections with an emphasis on BSL3 and BSL4 agents; (2) the general principles underlying the various imaging modalities; (3) application of preclinical in vivo imaging in drug discovery; and (4) the current approaches where in vivo imaging has been applied to evaluate viral and bacterial pathogens and drug/countermeasure interventions.

\section{Processes Involved in Viral and Bacterial Infections}

Viral and bacterial infections involve a series of steps that while not independent are pathogen and route of inoculation specific such as cellular uptake, replication and spread of the pathogen, and host specific such as modulation of the innate and adaptive immune response to the infectious agent. To identify the steps where in vivo imaging can play a role in better understanding the pathogenesis of the infectious agents, we will briefly review the life cycle of a viral agent, Venezuelan equine encephalitis virus (VEEV), and bacteria agent, Burkholderia pseudomallei, which are potential biothreat agents.

Alphaviruses are small, i.e., 65-70 $\mathrm{nm}$, encapsulated spherical particles containing a positive-strand genomic RNA of approximately $11.5 \mathrm{~kb}$ in length. Alphaviruses referred to as "old world" viruses such as Sindbis virus (SINV), Semliki Forest virus, Ross River virus (RRV), and Chikungunya (CHIKV) cause rheumatic diseases in humans [5]. The "new world" viruses, Venezuelan, Eastern, and Western equine encephalitis virus (VEEV, EEEV, WEEV), cause fatal encephalitic diseases in the Americas [6]. The general process of alphavirus infection (for review, see references [7-10]) is depicted in Fig. 1. The alphavirus binds to cell receptors mediated by the viral E2 glycoprotein and internalized in a clathrin-dependent manner. Under low $\mathrm{pH}$, the nucleocapsid is released into the cytoplasm through a fusion pore of viral and endosomal membranes where it disassembles to expose the RNA for translation in cytoplasmic vacuoles. The viral replicase complex assembles upon translation of the non-structural proteins with minus-strand RNA synthesis occurring early and both plus-strand and 


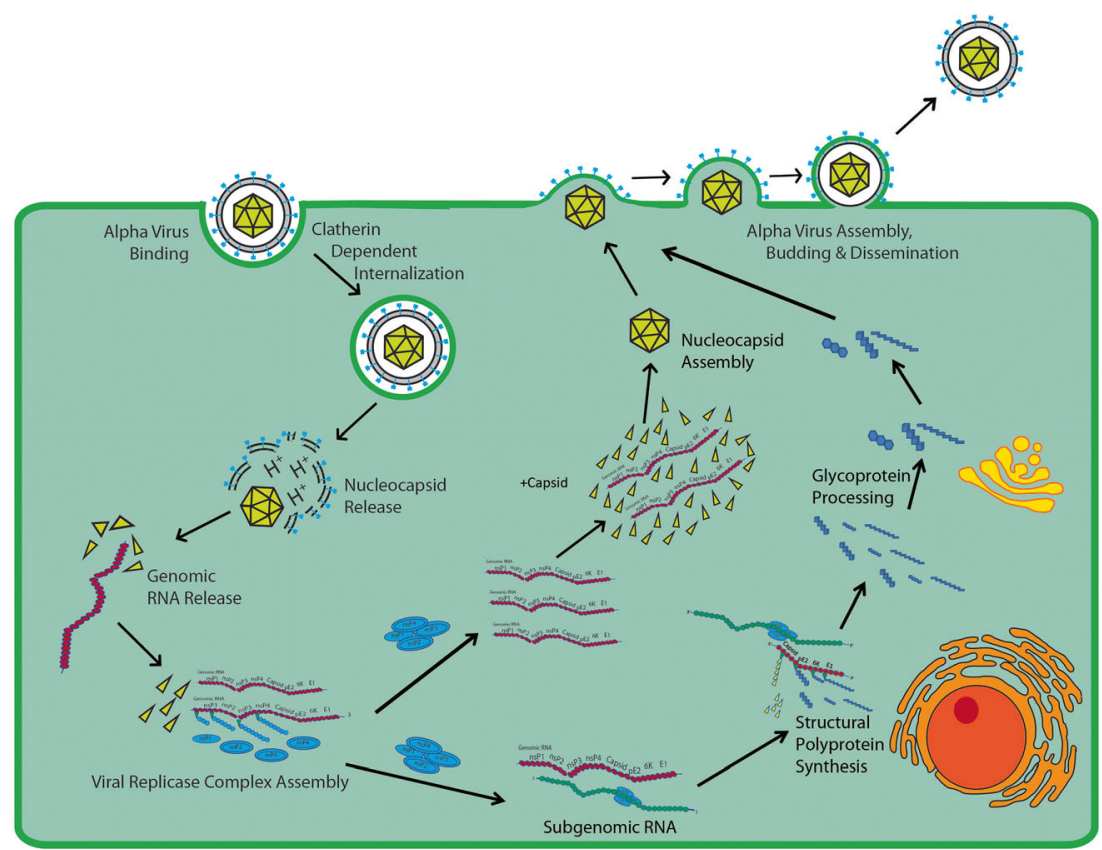

Fig. 1 Diagrammatic representation of the process of alphavirus infection.

subgenomic RNA synthesis occurring late in infection. Genomic RNA is transcribed while structural proteins involved in capsid formation are translated from subgenomic RNA as a polyprotein of capsid-pE2-6K-E1. The polyprotein inserts into the endoplasmic reticulum for further processing while the genomic RNA and capsid are assembled in the cytoplasm. Fusion of the newly synthesized nucleocapsid and viral glycoproteins occurs at the cell membrane and budding of new virus results. To mitigate an immune response, alphavirus infection shuts down the host transcription and translation processes without affecting virus replication, decreases IFN- $\alpha / \beta$ production which reduces the innate immune system and host anti-viral responses, and promotes cytopathic responses responsible for induction of the apoptotic pathway. In the cases of alphavirus-induced encephalitis and articular disease/myalgia, the hallmark host response is macrophage infiltration, cytokine and chemokine release, and edema.

$B$. pseudomallei is a gram-negative bacteria measuring $2-5 \mu \mathrm{m}$ in length and $0.5-0.8 \mu \mathrm{m}$ in diameter and which is endemic to tropical areas in Southeast Asia and Northern Australia. Infection with $B$. pseudomallei can occur via percutaneous inoculation, inhalation, or aspiration, and the sensitivity to infection and resulting melioidosis is dependent on the individual's immune status and presence of underlying conditions such as diabetes, renal disease, and alcohol abuse. The process of $B$. pseudomallei infection (see reference [11, 12] for review) is diagrammatically represented in Fig. 2. Following inhalation exposure, $B$. pseudomallei binds to the pharyngeal epithelial cell presumably through an asialoganglioside aGM1-aGM2 receptor complex mediated by the bacterial type IVA pili. The method of invasion of the bacteria into the cell is unknown, but the event is associated with rearrangement of the host actin cytoskeleton induced by the Burkholderia secretion apparatus (Bsa) type 3 secretion system (T3SS). In epithelial cells, $B$. pseudomallei represses inducible nitric oxide synthase (iNOS) by activating expression of a suppressor of cytokine signaling 3 (SOCS3) and cytokine-inducible src homology 2-containing protein (CIS). Upon phagocytic or non-phagocytic cellular uptake, the bacteria appear in vacuoles and with the aid of T3SS escapes into the cytoplasm where it replicates. In macrophages, replication continues without activating a bactericidal response. Repression of the bactericidal response is associated with a reduction in reactive oxygen or nitrogen intermediates. In macrophages, B. pseudomallei represses iNOS and interferon- $\beta$ expression by activating sterile- $\alpha$ and Armadillo motif (SARM) containing protein [13]. Bacterial spread is accomplished through macrophage lysis and through intracellular spread by membrane protrusions to nearby cells or by cell fusion to produce multi-nucleated giant cells. $B$. pseudomallei travel between cells by actin-mediated motility involving BimA to form actin tails. Dissemination of the bacteria within the host is likely accomplished through macrophages or transport through the lymphatic system within a polysaccharide and lipopolysaccharide capsule which protects the bacteria from complement-mediated killing and provide resistance to cationic peptides, respectively [11]. The acute host response to $B$. pseudomallei is a rapid influx and activation of neutrophils followed by macrophage infiltration and stimulation of an immune response mediated through Tolllike receptors (TLRs) 2 and 4 plus expression of the proinflammatory cytokines IL-6, IL-10, IL-12, IL-15, IL-18, TNF $\alpha$, and IFN $\gamma$ which contribute to the tissue destruction and pathogenesis of melioidosis. The cellular immune response requires the presence of macrophages and $\mathrm{CD} 4+\mathrm{T}$ cells, and 


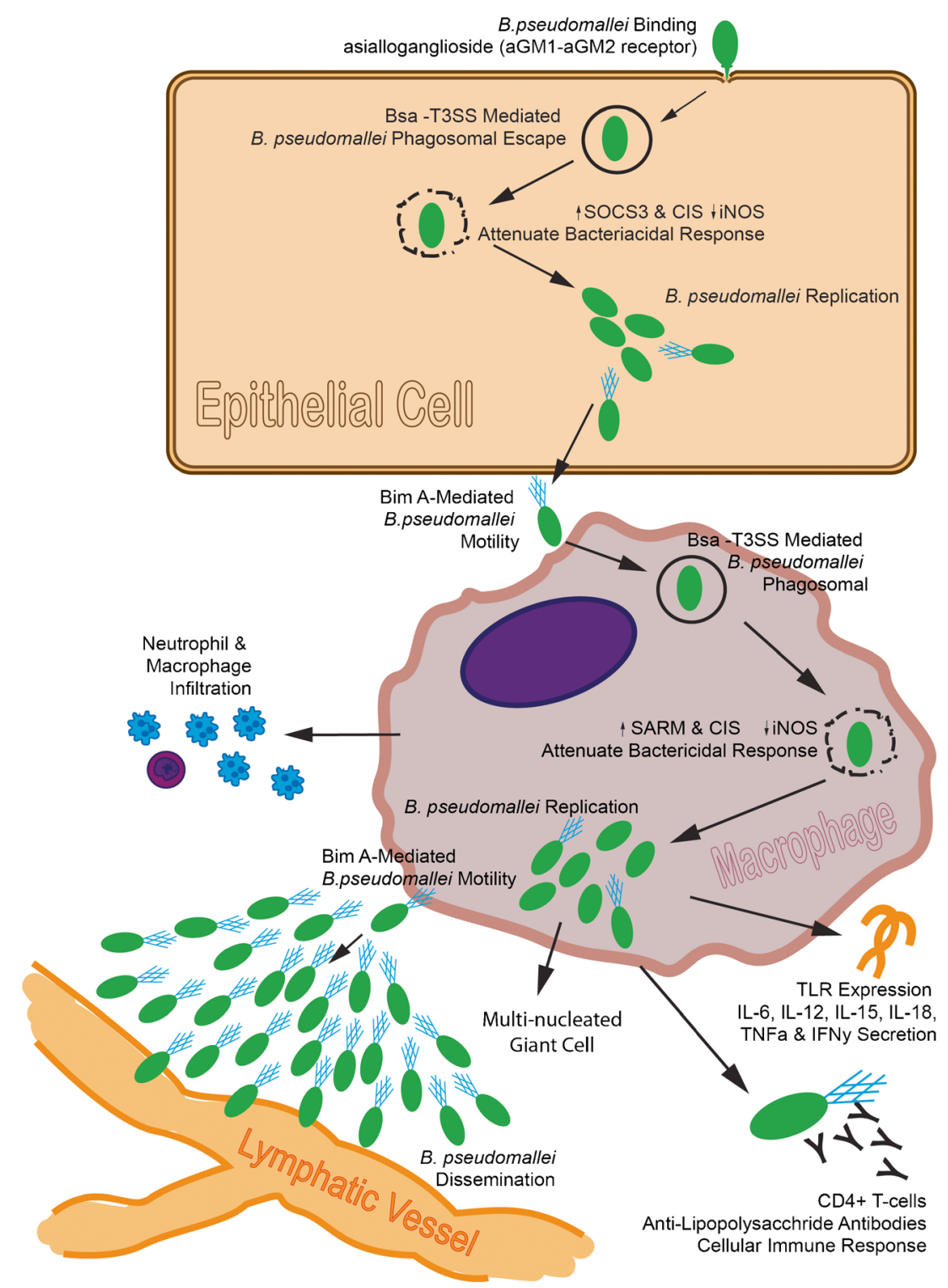

Fig. 2 Diagrammatic representation of Burkholderia pseudomallei infection.

anti-lipopolysaccharide antibodies appear to be a potential mechanism for bactericidal activity.

Host pathogen interactions are complex and involve a diverse range of mechanisms by which the pathogens can cause disease. However, the cellular process of infection typically involves common steps of binding, internalization, replication, muted host anti-viral and anti-bacterial response, budding, and distribution within the host to initiate disease. Disease initiation and progression, irrespective of alphavirus or B. pseudomallei infection, involves a pronounced inflammation of brain, joints, or lung resulting in encephalitis, arthralgia, or melioidosis, respectively. Beyond using optical and nuclear approaches to demonstrate the distribution of a modified pathogen containing a reporter construct, in vivo imaging could provide dynamic, serial information about disease progression following a viral and bacterial infection. Given the relative paucity of information utilizing imaging to study infectious agents, the subsequent sections will review applicable imaging tools used in the evaluation of disease processes of relevance to infectious agents, e.g., inflammation and neurologic disorders. In addition, the uses of imaging in drug discovery will be highlighted and specific applications of where imaging has been used to study infectious agents will be summarized.

\section{Imaging in Drug Discovery and Development}

\section{Basic Principles of Imaging}

Over the course of the last decade, imaging devices such as optical (bioluminescent and fluorescent), PET, SPECT, CT, US, and MRI have been developed for use in preclinical studies. Comparison of the resolution, sensitivity, and key 
features of each imaging modality is summarized in Table 1. Optical imaging is a measure of light emitted from a probe, e.g., green fluorescent protein and luciferase-luciferin, and used primarily in nude or non-pigmented mice, as a reporter of a specific cellular process or demonstration of the distribution of a target or cell. PET is a nuclear approach which detects two $511-\mathrm{keV}$ photons emitted at $180^{\circ}$ apart from an annihilation reaction of a positron produced from the decay of an unstable exogenously delivered tracer such as fluorine-18, carbon-11, and copper-64 coupled to a target molecule of interest, e.g., 2-deoxy-2- $\left[{ }^{18} \mathrm{~F}\right]$ fluoro-D-glucose $\left(\left[{ }^{18} \mathrm{~F}\right]-\mathrm{FDG}\right)$, which is used to measure a specific enzymatic, receptor, or protein interaction. When PET is coupled with $\mathrm{CT}$ or MRI, the radiotracer reagents can be co-localized to specific regions within organs with finer precision. SPECT imaging detects gamma-emitting isotopes, e.g., technetium99m (Tc-99m) and iodine-123 (I-123), conjugated to targets of interest much like PET, and some isotopes can be used to image molecules such as proteins and antibodies for longer periods of time. CT is a three-dimensional measure of X-ray attenuation properties of different tissues, and while lacking in innate contrast sensitivity, it provides very high spatial resolution, which is detector size and $\mathrm{X}$-ray dose-dependent. CT provides high-resolution structural images of bone and lung and with the addition of contrast agents is somewhat capable of soft tissue imaging. Ultrasound is a twodimensional measure of reflected high-frequency sound waves from a tissue of interest to create a structural image of the tissue in the transducer field-of-view and can be used in Doppler mode for perfusion with or without bubbles to improve contrast resolution. MRI is a three-dimensional measure of proton magnetization where image contrast is a function of the tissue environment within which the proton resides and can be interrogated with various techniques, e.g., bladder - may appear bright on a T2 sequence but dark on a $\mathrm{T} 1$ sequence. MRI like CT has very high soft tissue contrast resolution without the need for ionizing radiation. Taken together, optical, PET, and SPECT while not exclusively are best characterized as modalities amenable to molecular and functional imaging and CT, US and MRI are best utilized for anatomical imaging; however, some protocols with and without contrast agents have been developed to measure functional processes such as blood flow.

\section{Applications of Imaging in Drug Discovery}

Coincident with the development of the preclinical imaging tools, their application to the drug discovery and development process has become more widespread. Imaging is wellsuited to evaluate (1) the presence of a therapeutic target or drug at their specific site of action; (2) binding of the therapeutic to the target; and (3) expression of a pharmacologic effect either related to drug mechanism, efficacy, or safety. Applications of imaging for assessment of these three processes can be found in neuroscience, oncology, cardiovascular, and immunology. Examples, while not exhaustive with regard to what is available in the literature, are highlighted below to demonstrate how imaging has been applied to these disease areas to address the above three questions and to exemplify by extension how imaging can address processes of relevance to infectious diseases.

In neuroscience, the utilization of PET tracers has become a somewhat standard method for demonstrating brain receptor or enzyme expression and drug occupancy, while MRI is utilized to quantify structural and/or functional

Table 1. Comparison of the imaging modalities

\begin{tabular}{|c|c|c|c|}
\hline Imaging modality & Resolution $(\mu \mathrm{m})$ & Sensitivity & Key features \\
\hline \multirow[t]{4}{*}{ Optical } & 2,000 & $\mathrm{pM}-\mathrm{fM}$ & Two-dimensional \\
\hline & & & Limited depth of penetration \\
\hline & & & Molecular and functional imaging \\
\hline & & & Mice (nude or non-pigmented) only \\
\hline \multirow[t]{3}{*}{ PET } & $1,500-2,000$ & $\mathrm{nM}-\mathrm{pM}$ & Three-dimensional \\
\hline & & & Short- and long-lived isotopes \\
\hline & & & Molecular and functional imaging \\
\hline \multirow[t]{3}{*}{ SPECT } & $100-200^{\mathrm{a}}$ & $\mathrm{nM}-\mathrm{pM}$ & Three-dimensional \\
\hline & & & Potential for imaging multiple probes simultaneously \\
\hline & & & Molecular and functional imaging \\
\hline \multirow[t]{4}{*}{ CT } & $30+$ & $\mu \mathrm{M}$ & Three-dimensional \\
\hline & & & Primarily bone and lung imaging \\
\hline & & & Soft tissue imaging requires contrast agents \\
\hline & & & Anatomical imaging \\
\hline \multirow[t]{4}{*}{ Ultrasound } & $30+$ & $\mu \mathrm{M}$ & Two-dimensional \\
\hline & & & Depth of penetration dependent on transducer frequency \\
\hline & & & User dependent due to manual manipulation of transducers \\
\hline & & & Anatomical imaging \\
\hline \multirow[t]{3}{*}{ MRI } & $10+$ & $\mu \mathrm{M}$ & Three-dimensional \\
\hline & & & No ionizing radiation \\
\hline & & & Anatomical imaging ${ }^{\mathrm{b}}$ \\
\hline
\end{tabular}

${ }^{\mathrm{a}}$ Resolution is scanner dependent

${ }^{b}$ Potential for functional imaging using contrast agents 
processes such as flow, perfusion, diffusion, and neuronal activation. There are numerous examples of the use of imaging in the study of neuroscience, neuropathology, and drug intervention [14-16]. Most recently, a novel phosphodiesterase $2 \mathrm{~A}$ (PDE2A) tracer, 4- $\left(3-\left[{ }^{18} \mathrm{~F}\right]\right.$ fluoroazetidin-1yl)-7-methyl-5-\{1-methyl-5-[4-(trifluoromethyl)phenyl]-1Hpyrazol-4-yl $\}$ imidazo[5,1-f]-[1,2,4] triazine $\left(\left[{ }^{18} \mathrm{~F}\right] \mathrm{PF}\right.$ 05270430), was identified through a rational PET tracer design methodology [17]. In cynomologus monkeys, $\left[{ }^{18} \mathrm{~F}\right] \mathrm{PF}-05270430$ was used to demonstrate the distribution of PDE2A to brain striatum (putamen and caudate) and not cerebellum and while not shown such binding was noted to be blocked in a dose-dependent manner by a specific PDE2A inhibitor [17]. When the tissue distribution, drug binding to a specific target and PK data are taken together, one can correlate plasma drug levels with the specific target occupancy needed for drug efficacy. Novel PET tracers have been used to characterize the progression of disease such as Alzheimer's by quantifying the deposition of beta-amyloid [18-20]. More general PET tracers such as $\left[{ }^{18} \mathrm{~F}\right]-\mathrm{FDG}$ can be used to discern changes in brain metabolism and drug effects related to both efficacy and safety. Magnetic resonance imaging and MR spectroscopy have been used to further characterize Alzheimer's disease pathology by assessing changes in brain size [21] and neuroinflammation by measuring myoinositol levels [21, 22].

Application of imaging to the diagnosis and assessment of treatment in oncology has been long-standing. Multimodality approaches (for review, see [23]) have been used preclinically to characterize growth and metastasis of xenograft tumors and orthotopic tumors because the traditional caliper measurements inconsistently follow functional changes. Measures of tumor metabolism and proliferation have employed 2-deoxy-2- $\left[{ }^{18} \mathrm{~F}\right]$ fluoro-D-glucose $\left(\left[{ }^{18} \mathrm{~F}\right] \mathrm{FDG}\right)$ and $\left[{ }^{18} \mathrm{~F}\right]$ fluoro-3-dexoythymidine $\left(\left[{ }^{18} \mathrm{~F}\right] \mathrm{FLT}\right) \mathrm{PET}$, respectively. Staging the degree of tumor proliferation with $\left[{ }^{18} \mathrm{~F}\right] \mathrm{FLT}$ has provided more consistent cohorts of animals for drug testing, reduced variability in the measurement, and demonstrated a pharmacologic effect prior to tumor size changes [24, 25]. Dynamic contrast-enhanced MRI (dceMRI) is routinely used to characterize tumor angiogenesis and changes in blood flow following treatment [26]. From a preclinical perspective, optical imaging of tumors containing fluorescent or bioluminescent reporter constructs has enabled rapid compound testing and staging of tumor growth prior to applying the more complex PET, SPECT, or MRI approaches. In addition to assessing drug mechanism or efficacy, imaging has been used to phenotype tumors, e.g., expression of carcinoembryonic antigen [27], to better define the appropriate course of clinical treatment and to select potentially more responsive patient cohorts.

Cardiovascular imaging has focused primarily in the areas of atherosclerosis and diabetes to characterize disease progression and disease-modifying therapies. $\left[{ }^{18} \mathrm{~F}\right] \mathrm{FDG}$ is used as a marker of vascular inflammation because macrophages resident within the atherosclerotic lesion exhibit an increased metabolic activity [28, 29]. Treatment with simvastatin reduces macrophage accumulation within human atherosclerotic plaques and decreases $\left[{ }^{18} \mathrm{~F}\right] \mathrm{FDG}$ activity consistent with such findings [30]. In diabetes, to quantify the mass of pancreatic $\beta$-islet cells, a novel tracer, $\left[{ }^{11} \mathrm{C}\right]$ dihydrotetrabenazine, which targets $\beta$-cell vesicular monoamine transporter type II (VMAT2) has been shown to detect pancreatic $\beta$-islet cells and reduction in cell mass in streptozotocin-treated and Zucker rat models of diabetes [31] and in human type I diabetics [32].

Immunological responses such as with inflammation are present across multiple disease areas, and applications for imaging can be found in rheumatoid arthritis [33] and atherosclerosis [28-30] as noted above and infection and general inflammation [34]. In general, $\left[{ }^{18} \mathrm{~F}\right] \mathrm{FDG}$ has been used substantially to assess inflammation. More selective markers for the peripheral-type benzodiazepine receptor (PBR) or what is also referred to as the $18-\mathrm{kDa}$ translocator protein (TSPO), R- $\left[{ }^{11} \mathrm{C}\right] \mathrm{PK} 11195$, can be used to more directly demonstrate the presence of macrophages within the area of inflammation. For infectious diseases, imaging has been used to monitor the pathogen through direct labeling of the pathogen (a more detailed description is below) and assessment of the host response through monitoring inflammatory mediators and cellular and vascular responses [33]. For example, general markers of inflammation like $\left[{ }^{18} \mathrm{~F}\right] \mathrm{FDG}$, more selective cellular markers involving direct labeling of neutrophils with a copper-64- or Tc-99m-labeled peptides which bind to the formyl peptide receptor [35-37] or direct labeling of monocyte/macrophages with In-111, R$\left[{ }^{11} \mathrm{C}\right] \mathrm{PK} 11195$, or tracers of matrix degradation, i.e., matrix metalloproteinases (MMPs), and tools for assessment of host responses involved in transcriptional regulation, i.e., NF- $\mathrm{kB}$, and apoptosis, e.g., Tc-99m-labeled annexin $\mathrm{V}$, have been used [38]. The combination of imaging methodologies provides a more thorough understanding of the molecular, cellular, tissue, and organ response to a pathogen or insult that result in an inflammatory response.

Individual and multi-modality imaging approaches can be used to better characterize infections caused by biothreat agents, assess the time course of infection and host response, and evaluate drug distribution, drug targeting, and drug efficacy. Table 2 summarizes the types of physiologic responses and imaging methods used to evaluate the pathophysiology of disease in numerous therapeutic areas and in drug discovery and development that are equally amenable for studying infectious agents. Development of new reporter constructs containing receptor or enzyme reporters in BSL3/4 agents would be beneficial to characterize the distribution and time course of infection within both rodent and non-rodent models using PET and SPECT imaging. Direct labeling of known and novel drugs with PET and SPECT radiotracers serves not only to demonstrate drug biodistribution but also to link plasma and tissue drug levels with pathogen load. Measures of tissue function, metabolism, and activation, i.e., $\left[{ }^{18} \mathrm{~F}\right] \mathrm{FDG}-\mathrm{PET}$, magnetic 
Table 2. Applications of imaging for the assessment of disease pathophysiology and drug intervention

\begin{tabular}{|c|c|c|c|c|c|c|}
\hline & Imaging modality & & & & & \\
\hline & Optical & PET & SPECT & CT & Ultrasound & MRI \\
\hline \multirow{2}{*}{$\begin{array}{l}\text { Physiologic process } \\
\text { Gene expression }\end{array}$} & & & & & & \\
\hline & $\begin{array}{l}\text { Luciferase-luciferin } \\
\text { Green fluorescent } \\
\text { protein (GFP) } \\
\text { luxABCDE operon } \\
\text { Red-shifted firefly } \\
\text { luciferase (FFlucRT) }\end{array}$ & $\begin{array}{l}{\left[{ }^{124} \mathrm{I} /{ }^{18} \mathrm{~F}\right] \mathrm{FIAU}} \\
{\left[{ }^{18} \mathrm{~F}\right] \mathrm{FHBG}} \\
{\left[{ }^{18} \mathrm{~F}\right] \mathrm{FMAU}} \\
{\left[{ }^{18} \mathrm{~F}\right] \text { fluromethyl-spiperone }} \\
{ }^{124} \mathrm{I} \\
{\left[{ }^{18} \mathrm{~F}\right] \text { penciclovir }}\end{array}$ & $\begin{array}{l}{\left[{ }^{125} \mathrm{I}\right] \text { FIAU meta- }} \\
{\left[{ }^{123} \mathrm{I}\right] \text { iodobenzyl- }} \\
\text { guanidine } \\
{ }_{123,131} \mathrm{I}\end{array}$ & & & $\begin{array}{l}\text { Fe-transferrin } \\
\text { receptor }\end{array}$ \\
\hline Target expression & $\begin{array}{l}\text { Fluorescent dye- } \\
\text { conjugated } \\
\text { maltodextrin }\end{array}$ & $\begin{array}{c}{\left[{ }^{18} \mathrm{~F}\right\},\left[{ }^{11} \mathrm{C}\right],\left[{ }^{64} \mathrm{Cu}\right],\left[{ }^{89} \mathrm{Zr}\right]-} \\
\text { labeled molecules }\end{array}$ & $\begin{array}{c}{\left[{ }^{111} \mathrm{In}\right],\left[{ }^{123} \mathrm{I}\right],\left[{ }^{131} \mathrm{I}\right]} \\
{\left[{ }^{99 \mathrm{~m}} \mathrm{Tc}\right] \text {-labeled }} \\
\text { molecules }\end{array}$ & & & $\begin{array}{l}\text { Chemical exchange } \\
\text { saturation transfer } \\
\text { (CEST) }\end{array}$ \\
\hline Target binding & & $\begin{array}{l}{\left[{ }^{18} \mathrm{~F}\right\},\left[{ }^{11} \mathrm{C}\right],\left[{ }^{64} \mathrm{Cu}\right],\left[{ }^{89} \mathrm{Zr}\right]-} \\
\text { labeled molecules }\end{array}$ & $\begin{array}{c}{\left[{ }^{111} \mathrm{In}\right],\left[{ }^{123} \mathrm{I}\right],\left[{ }^{131} \mathrm{I}\right]} \\
{\left[\begin{array}{l}\left.{ }^{99 \mathrm{~m}} \mathrm{Tc}\right]- \text { labeled } \\
\text { molecules }\end{array}\right.}\end{array}$ & & & \\
\hline Drug PK/PD & & $\begin{array}{l}{\left[{ }^{18} \mathrm{~F}\right\},\left[{ }^{11} \mathrm{C}\right],\left[{ }^{64} \mathrm{Cu}\right],\left[{ }^{89} \mathrm{Zr}\right]-} \\
\quad \text { labeled molecules }\end{array}$ & $\begin{array}{l}{\left[{ }^{111} \mathrm{In}\right],\left[{ }^{123} \mathrm{I}\right],\left[{ }^{131} \mathrm{I}\right],} \\
{\left[{ }^{99 \mathrm{~m}} \mathrm{Tc}\right]-\text { labeled }} \\
\text { molecules }\end{array}$ & & & \\
\hline \multicolumn{7}{|l|}{ Tissue function } \\
\hline Metabolism & & $\begin{array}{l}{\left[{ }^{18} \mathrm{~F}\right] \mathrm{FDG},\left[{ }^{11} \mathrm{C}\right] \text { lysine }} \\
{\left[{ }^{11} \mathrm{C}\right] \mathrm{palmitic} \text { acid, }} \\
{\left[{ }^{11} \mathrm{C}\right] \text { leucine, }} \\
{\left[{ }^{11} \mathrm{C}\right] \text { methionine }} \\
{\left[{ }^{11} \mathrm{C}\right] \text { tyrosine, }\left[{ }^{11} \mathrm{C}\right] \text { deprenyl, }} \\
{\left[{ }^{18} \mathrm{~F}\right] \text { deoxyuracil }}\end{array}$ & & & & $\begin{array}{l}\text { MRS-glutamine, } \\
\text { glutamate, choline, } \\
\text { creatinine } \\
{ }^{13} \mathrm{C}-,{ }^{31} \mathrm{P}-\mathrm{MRS}\end{array}$ \\
\hline Proliferation & & {$\left[{ }^{18} \mathrm{~F}\right] \mathrm{FLT}$} & & & & \\
\hline Apoptosis & & $\begin{array}{l}{\left[{ }^{18} \mathrm{~F}\right] \text {-labeled annexin } \mathrm{V}} \\
{\left[{ }^{18} \mathrm{~F}\right] \mathrm{ML} 10} \\
{\left[{ }^{18} \mathrm{~F}\right] \mathrm{ICMT}-11} \\
{\left[{ }^{18} \mathrm{~F}\right] \mathrm{CP} 18}\end{array}$ & ${ }^{99 \mathrm{~m}}$ Tc-labeled annexin $\mathrm{V}$ & & & \\
\hline Hypoxia & & {$\left[{ }^{64} \mathrm{Cu}\right]$ ATSM } & & & & \\
\hline Blood flow & & {$\left[{ }^{15} \mathrm{O}\right]$ water } & & $\begin{array}{l}\text { Iodine contrast } \\
\text { agents }\end{array}$ & Microbubbles & $\begin{array}{l}\text { Arterial spin labeling } \\
\text { MRI (ASL) } \\
\text { Blood oxygen level- } \\
\text { dependent MRI } \\
\text { (BOLD) } \\
\text { Dynamic contrast- } \\
\text { enhanced MRI } \\
\text { (dceMRI) }\end{array}$ \\
\hline \multicolumn{7}{|l|}{ Cell markers } \\
\hline Inflammatory & $\begin{array}{l}\text { GFP-transgenic } \\
\text { mice }\end{array}$ & $\begin{array}{l}\mathrm{R}-\left[{ }^{11} \mathrm{C}\right] \text { PK } 11195 \\
{\left[{ }^{18} \mathrm{~F}\right] \text { FEAnGA }} \\
{\left[{ }^{18} \mathrm{~F}\right] \text { FEDAC }}\end{array}$ & $\begin{array}{l}{ }^{64} \mathrm{CU} \text { or }{ }^{99 \mathrm{~m}} \mathrm{Tc} \text {-labeled } \\
\text { peptides } \\
{\left[{ }^{125} \mathrm{I}\right] \mathrm{DPA} 173}\end{array}$ & & & $\begin{array}{l}{ }^{19} \mathrm{~F}-\mathrm{MRS} \\
{ }^{19} \mathrm{~F} \text { perfluorocarbon } \\
\text { MRS }\end{array}$ \\
\hline Neurons & & $\begin{array}{l}{\left[{ }^{18} \mathrm{~F}\right] \text { fluorodopa }} \\
{\left[{ }^{11} \mathrm{C}\right] \text { ephedrine }}\end{array}$ & & & & $\begin{array}{l}\text { MRS-choline } \\
\text { Diffusion tensor } \\
\quad \text { imaging (dti-MRI) }\end{array}$ \\
\hline Glial cells & & $\mathrm{R}-\left[{ }^{11} \mathrm{C}\right] \mathrm{PK} 11195$ & & & & MRS-myoinositol \\
\hline Organ structure & & & & $\begin{array}{l}\text { Bone and lung } \\
\text { imaging } \\
\text { Soft tissue imaging } \\
\text { with contrast } \\
\text { agents }\end{array}$ & Soft tissue & Proton MRI \\
\hline
\end{tabular}

resonance spectroscopy (MRS), ASL-MRI, and BOLDMRI, cell markers, i.e., $\left[{ }^{18} \mathrm{~F}\right]$ FEDAC and inflammation, changes in changes in cell phenotype and apoptosis, i.e., Tc$99 \mathrm{~m}$-labeled annexin $\mathrm{V}$, and measures of organ/tissue structure i.e., MRI, CT, and ultrasound, all provide tools to dynamically evaluate the host response to the BSL3/4 agent.

Based on a review of the literature, imaging has demonstrable advantages over classical methods used for the discovery and development of drugs. Besides reducing the number of animals used in a study, in vivo imaging allows one to perform whole body scans, dynamically, with higher statistical power given that each animal can act as its own control and with greater flexibility than classical methods such as histology. Histology is a sensitive measure of disease pathology at a single time point. When imaging is coupled with histology, imaging can be used to dynamically measure disease progression and select cohorts of animals with a similar state of disease for histologic assessment or drug intervention. Imaging approaches as noted in this section have been successfully utilized to characterize a compound's mechanism of action; to provide a proof of concept or mechanism that a new drug entity engages their 
respective target; to demonstrate a pharmacologic effect that can provide patient benefit; or to define a drug dose range which is linked to target engagement and where side effects are limited or mitigated. Similar types of questions also exist in the development of countermeasures against high consequence pathogens such as biothreat agents, and application of imaging approaches can provide confidence in the animal model, drug mechanism/target, or drug pharmacodynamics and aid drug development.

\section{Imaging Applications for Viruses and Bacteria}

Imaging applications can be divided into the evaluation of the pathogen specifically and the host response to the pathogen. While all imaging modalities have the potential to assess the pathogen directly, optical and nuclear imaging are typically used because of their inherent sensitivity. Nuclear, MRI, and CT imaging are well suited for assessment of the host response to the pathogen, e.g., morphological changes, organ metabolism, inflammation, and hemodynamics. In the subsequent sections, each approach will be reviewed and divided on the basis of pathogen and host approaches where applicable.

\section{Viral and Bacterial Reporter Constructs}

Viruses engineered with reporter constructs such as enzymes and receptors are amenable to detection by imaging and used to evaluate the biodistribution of viruses containing specific therapeutic or gene transfer payloads. Similarly engineered BSL3/4 viruses can be used to study the virus itself. Numerous reporter constructs have been developed that are detectable by optical, PET, or SPECT imaging. The most often used reporter is herpes simplex virus thymidine kinase (HSV-tk1) with either $\left[{ }^{124} \mathrm{I} /{ }^{18} \mathrm{~F}\right]-29$ fluoro-29-deoxy-1-b-D-arabinofuranosyl-5-iodouracil ([ ${ }^{124} \mathrm{I} /$ $\left.\left.{ }^{18} \mathrm{~F}\right] \mathrm{FIAU}\right)$ or 9-(4-[ $\left.{ }^{18} \mathrm{~F}\right]$ fluoro-3-(hydroxymethyl)butyl] guanine $\left(\left[{ }^{18} \mathrm{~F}\right]-\mathrm{FHBG}\right)$ as the enzyme substrate and PET as the imaging modality [39-52]. The viral thymidine kinase is translated in the cell along with the viral RNA and phosphorylates the exogenously delivered radiolabeled $\left[{ }^{124} \mathrm{I} /{ }^{18} \mathrm{~F}\right]$ FIAU or $\left[{ }^{18} \mathrm{~F}\right] \mathrm{FHBG}$ substrate, trapping it in cells and thereby labeling cells which have been infected with the virus. Alternative reporter enzymes such as human mitochondrial thymidine kinase 2 (hmtk2) [43] and human deoxycytidine kinase (hdCK) [43] utilizing $2^{\prime}$-deoxy-2- $\left[{ }^{18} \mathrm{~F}\right]$ fluoro-5-methyl-1- $\beta$-Larabinofuranosyluracil ([ $\left.\left[{ }^{18} \mathrm{~F}\right]-\mathrm{FMAU}\right)$ and $2^{\prime}$-deoxy-2'$\left[{ }^{18} \mathrm{~F}\right]$ fluoroarabinofuranosylcytosine as substrates, respectively, have been developed to avoid immunologic reactions in humans. The varicella zoster virus thymidine kinase (VZV-tk) in combination with radiolabeled bicyclic nucleoside analogs as enzyme substrates is currently being evaluated as a potential reporter construct [45].
Several receptor-based reporter systems such as the rat/ human sodium iodide symporter (NIS) [46-48], human norepinephrine transporter (hNET) [49], human somatostatin receptor (hSSTR2) [50], and rat dopamine D2 receptor (D2R) [51] have been incorporated into viruses. Radiotracers amenable for PET or SPECT are available to quantify expression of the different receptors following viral infection. The NIS reporter system is attractive because I-123, I124, I-131, and Tc-99m pertechnetate can be used which obviates the need for complex chemistry [51]. The hNET reporter system has the advantage of being easily incorporated into the virus because of the small size of the gene cassette [52]. The radiotracers used for detection of hNET are iodine-123, iodine-131, and meta- $\left[{ }^{123 / 124} \mathrm{I}\right]$ iodobenzylguanidine. While hSSTR2 tracers such as $\left[{ }^{68} \mathrm{Ga}\right]$ DOTATOC, $\left[{ }^{68} \mathrm{Ga}\right]$ DOTATATE, and $\left[{ }^{111} \mathrm{In}\right]$ DOTABASS provide high specific binding and low background due to their rapid clearance, the fact that DOTATOC and DOTATATE are agonists for the $\mathrm{G}$ protein-coupled receptor, they can perturb cellular function and confound the interpretation of the results. Incorporation of the D2R into a virus and imaging receptor expression with $\left[{ }^{18} \mathrm{~F}\right]$-fluromethyl-spiperone has been utilized; however, the use of a mutant (D2R80A) proved more valuable because it completely uncoupled ligand binding with activation of $G$ protein-linked signaling and adverse effects on the transduced cells [51]. Similar receptor-based systems can be constructed with an MRI detectable reporter, e.g., transferrin receptor and iron accumulation [53, 54]. Despite significant spatial resolution, such MRI-based approaches lack the sensitivity of nuclear and optical approaches and present potential artifacts due to the longevity of the signal that may be associated with remnants of cells containing the iron particles. With regard to creating reporter systems in bacteria, less work has been done.

While reporter systems have been developed to track therapeutic genes associated with gene therapy, or stem cells to assess viability and longevity or to act as radiolabeled suicide molecules for oncolytic therapy, the procedures developed for insertion of such reporters and evaluation of their functionality can also be applied to studying the virus or bacterial particle itself. Optical imaging and viruses/ bacteria containing reporter constructs such as luciferase/ luciferin or green fluorescent protein which are amenable to optical imaging have been utilized to evaluate pathogens and are reviewed in the next section.

\section{Optical Imaging}

Bioluminescence approaches have been utilized to characterize the biodistribution of viral and bacterial pathogens post-infection. Luciferase which requires exogenous luciferin administration or the lux operon containing both luciferase and luciferin has been transfected into murid herpesvirus-4 [55], varicella zoster [56], Venezuelan equine encephalitis [57], Chikungunya [58], cowpox [59], and 
murine cytomegalovirus [60] viruses and bacteria such as Staphylococcus aureus [61], enteropathogenic Escherichia coli, and enterohemorrhagic E. coli [62], Bacillus anthracis [63], Yersinia pestis [64-66], Francisella tularensis [67], and Burkholderia mallei and pseudomallei [68,69]. Incorporation of the optical reporter in the virus/bacteria noted above was shown to not markedly affect growth rate, survival, and infectivity and functioned similarly to the wild-type pathogen. Factors influencing the expression of the bioreporter were the choice of promoter, size of the amino acid flanking regions, and whether the construct was inserted randomly or site-specifically. The bioreporters allowed for whole body detection of pathogens, and assessment of the time course of infection and the bioluminescent signal was highly sensitive with the signal intensity correlating to pathogen number.

Site-directed insertion of the luciferase construct is important in preserving viral function, and when coupled with the constitutive native promoters for specific viral proteins, optical imaging can be used to assess early and late stage viral replication. Insertion of the luciferase expression cassette in murid herpesvirus- 4 between open reading frames open reading frames (ORF) 57 and 58 which are involved in lytic replication and viral spread allowed for the monitoring of virus distribution and function by bioluminescence [55]. The addition of the bioreporter was shown to not markedly affect viral functions. In varicella zoster virus, placement of click beetle luciferase in-frame with ORFs 63,68 , and 70 and under their constitutive promoters not only allowed for optical imaging of the virus but also monitoring of IE63 and gE luciferase fusion proteins which are involved in early and late varicella replication, respectively [56]. These two studies demonstrate that placement of the reporter constructs can provide more than just virus location but also information about the functioning of the virus and the role of specific viral proteins in replication and intercellular infection.

Viral luciferase expression in combination with whole body optical imaging has been used to characterize different routes of viral infection and drug efficacy. Intranasal infection with murid herpesvirus-4 resulted in nasal and lung expression of luciferase activity and abdominal organ expression following intraperitoneal infection, while no signal was detected following oral administration [55]. Intranasal infection with VEEV containing a luciferase bioreporter demonstrated brain uptake of the virus 3 days prior to clinical signs [57]. Chikungunya virus with a luciferase reporter injected into the mouse footpad resulted in local bioluminescence but not systemic signal [58]. Treatment of varicella virus-infected mice with valacyclovir [56] and VEEV-infected mice with Ampligen, a TLR-3 agonist [57], resulted in a decrease in luciferase luminescence which is suggestive of a reduction in viral replication. It is interesting to note that optical imaging was also able to detect upon withdrawal of valacyclovir that the luminescence signal reappeared, reflecting renewed viral replication. Cidofovir treatment at doses of 25 and $100 \mathrm{mg} / \mathrm{kg}$ administered intraperitoneal (i.p.) to mice infected with a green fluorescent protein (GFP)-expressing cowpox virus significantly reduced the bioluminescent signal which is indicative of reduced viral replication when the animals were imaged post-mortem [59]. In mice infected with a GFP-expressing mouse cytomegalovirus (GFP-MCMV), i.p. administration of $100 \mathrm{mg} / \mathrm{kg}$ and subcutaneous (s.c.) administration of $50 \mathrm{mg} / \mathrm{kg}$ ganciclovir decreased the fluorescent signal [60]. Treatment of GFPMCMV mice with $50 \mathrm{mg} / \mathrm{kg}$, s.c., of a novel compound identified by screening, 1-(3,5-dichloro-4-pyridyl) piperidine4-carboxamide (DPPC), delayed the appearance of a muted fluorescent signal [60]. These data taken together indicate that optical imaging is a sensitive tool capable of characterizing virus distribution, the effect of drug intervention and discerning differences between dose and route of drug administration.

Dynamic, real-time optical imaging of bacteria transfected with various bioluminescent reporters has exposed pathways of infection which were previously undetected. Construction of $B$. anthracis containing the lux operon established that following inhalation and cutaneous infections, the $B$. anthracis spores germinated at the site of inoculation while Peyer's patches were the main site of bacterial growth following intragastric inoculation [63]. Contrary to our current understanding, optical imaging established that $B$. anthracis germination occurred at the site of inoculation and initially did not require transport to the draining lymph nodes for propagation, but eventually all routes of infection progressed to the lymph nodes. Following intranasal $B$. mallei infection, a strong luminescent signal was observed in the lung that could be reduced by intraperitoneal administration of levofloxacin, $24 \mathrm{~h}$ post-infection [68]. Similarly, intranasal B. pseudomallei exhibited a similar pattern of infection but in addition optical imaging demonstrated that the olfactory nerve was the route of entry for the bacteria into the brain, and such entry occurred prior to bacteria being detected in the blood [69]. Y. pestis which is a gram-negative bacterium capable of causing bubonic, septicemic, and pneumonic plague has been evaluated utilizing optical imaging approaches to track both level and distribution of infection and the effect of pharmacologic intervention [64-66]. Insertion of the luxCDABE operon driven by either the PtolC or PcysZK promoter into $Y$. pestis provided a tool to evaluate differing routes of administration, i.e., intradermal, subcutaneous, or intranasal. With the intradermal and subcutaneous routes, bioluminescence from the LuxPcysZK strain was detectable in the draining lymph nodes followed by systemic dissemination while intranasal exposure localized the signal to the lungs and thoracic cavity [64]. Utilization of a non-disseminating LuxPcysZK $\Delta$ pla construct demonstrated that the bioluminescent signal was confined to the site of inoculation as expected. Some investigators [65] have also shown that bioluminescence signal from $Y$. pestis CO92 pLux is capable of detecting $10^{4}$ $-10^{5} \mathrm{cfu}$ and is linearly correlated with the degree of infection. Unlike excising the organs and counting colonies, the optical imaging approach monitored the fairly variable progression of infection in each animal, staging the degree of infection for treatment group selection and thereby reducing the variability 
in the measurement. Levofloxacin treatment $(10 \mathrm{mg} / \mathrm{kg} /$ day for 6 days, $24 \mathrm{~h}$ after infection) significantly reduced the luminescent signal indicating that the treatment killed the bacteria [66]. Thus, for B. anthracis, B. mallei, B. pseudomallei, and $Y$. pestis, optical imaging was a powerful tool to track the course of infection, define new pathways of infection, and sensitive enough to discern changes due to drug treatment.

Beyond using optical imaging to assess the degree and localization of bacterial infections, it can also be coupled with other optical reporters to better understand the pathophysiology of the disease and consequences of drug intervention. For example, in a skin wound model, a bioluminescent $S$. aureus strain (SH1000) was used to track the course of wound infection [61]. Performing the same experiment in LysEGFP mice, which possesses green fluorescent neutrophils, one was able to assess both bacterial infection and degree of inflammation as assessed by neutrophil infiltration using bioluminescence and fluorescent optical imaging. Optical imaging has also proved viable for the assessment of vancomycin-rifampin efficacy against $S$. aureus-induced prosthetic joint infection in mice [70].

Improvements in optical reagents are ongoing to both increase the sensitivity of optical imaging and to be able to image deeper organ structures. Incorporation of a red-shifted derivative of firefly luciferase (FFlucRT) into Mycobacterium tuberculosis [71] or use of a near-infrared fluorogenic substrate against the endogenous $M$. tuberculosis $\beta$ lactamase [72] increased sensitivity to detect $10^{4}$ and $10^{2}$ colony-forming units, respectively. The red-shifted and nearinfrared agents also increased the depth from which the optical signal can be detected. Targeting specific bacterial transport pathways or secreted enzymes has also proved viable for use in detecting infection. For example, fluorescent dye-conjugated maltodextrin-based imaging probes are internalized in bacteria expressing the specific transporter and can be used for detection of these bacteria [73]. Probes which are normally silent but fluoresce when activated by secreted nucleases have been used to demonstrate the distribution of $S$. aureus in infected animals [74]. Thus, generation of general and targeted reagents is another mechanism to improve the utility and sensitivity of optical imaging.

Optical imaging while limited to mouse models of infection has established the utility of imaging to better understand viral and bacterial infections, routes of infection, and the effect of drug intervention. Based on what has been learned through optical imaging, one would expect that similar tools could be built for use in nuclear imaging, i.e., PET and SPECT. The methods employed to build the tools for optical imaging can be instructive in building the pathogen constructs amenable to nuclear imaging. The nuclear imaging tools broaden applicability from rodents to primates due to the ability of imaging deeper organs and as such expand the number of animal models within which to evaluate viral/bacterial distribution and pathophysiology.
The opportunity to evaluate viral/bacterial pathogens in non-rodent models also provides a mechanism to evaluate drugs for the treatment of BSL3/4 agents in models which might be more predictive of the human condition and aid in the registration of new drug applications under the U.S. FDA Animal Rule.

\section{Nuclear Imaging}

Despite the amount of work performed with optical imaging to develop transduced viruses as tools to monitor gene therapy, oncolytic therapy, and stem cell survival [39-54], a minimal amount of work has been done to develop tools amenable to nuclear imaging to directly characterize viral/ bacterial distribution. A few examples utilizing bacteria have been reported. Direct labeling of an attenuated Salmonella abortusovis with technetium-99m was performed and evaluated in sheep [75]. Labeling efficiency was low, i.e., $30 \%$, but bacterial viability was unchanged and the investigators were able to discern the spatial and temporal patterns of bacteria dissemination in the lymphatic system following a sub-cutaneous injection. Several other investigators utilizing Tc-99m or indium-111 (In-111) directly labeled Pseudomonas aeruginosa, E. coli, Streptococcus, and S. aureus to perform similar types of experiments [76-81]. While labeling the pathogen directly appears to be a viable approach, only acute evaluation is possible given that with bacterial replication the signal is diluted and the potential for freely circulating radiolabel can confound the results. Several studies utilized the constitutively expressed bacterial thymidine kinase (TK) or transfected TK and the substrate, 1-(29deoxy-29-fluoro-b-Darabinofuranosyl)-5$\left[{ }^{125} \mathrm{I}\right]$ iodouracil $\left(\left[{ }^{125} \mathrm{I}\right] \mathrm{FIAU}\right)$, which is amenable to SPECT imaging to monitor bacterial infections. Constitutively expressed bacterial TK in E. coli, Enterococcus faecalis 49532, Staphylococcus pneumonia 49619, Staphylococcus aureus 29213 and 25293, Staphylococcus epidermidis F362 were successfully imaged by SPECT using $\left[{ }^{125} \mathrm{I}\right] \mathrm{FIAU}$ to demonstrate distribution post-infection [82]. Others have also shown that the $\left[{ }^{125} \mathrm{I}\right] \mathrm{FIAU}$ signal is strongly correlated with bacterial $E$. coli load with a limit of detection of $10^{9}$ colony-forming units $/ \mathrm{ml}$ [83]. In bacteria not expressing TK, incorporation of bacterial TK into $M$. tuberculosis under the HSP60 promoter generated a tool (M. tuberculosis Phsp60 TK) for use in assessing infection associated with tuberculosis [84]. As with the other studies noted above, SPECT imaging utilizing $\left[{ }^{125} \mathrm{I}\right]$ FIAU was used to assess the degree of bacterial infection and localization of the bacteria in the lung.

A few studies employing nuclear imaging approaches have focused on studying the pathophysiology of infection and the distribution of therapeutics designed to treat the infection. Neuroinflammation related to exposure to herpes simplex virus 1 (HSV-1) was assessed by PET by quantifying $\beta$-glucuronidase secretion from activated microglia and by direct labeling 
of activated microglia using a marker for the PBR [85]. To measure $\beta$-glucuronidase activity, a PET tracer, 1-O-(4-(2$\left[{ }^{18} \mathrm{~F}\right]$ fluoroethyl-carbamoyloxymethyl)-2-nitrophenyl)-O- $\beta$-Dglucopyronuronate $\left(\left[{ }^{18} \mathrm{~F}\right] \mathrm{FEAnGA}\right)$, which acts as a substrate for the enzyme was synthesized. Upon cleavage of $\left[{ }^{18} \mathrm{~F}\right]$ FEAnGA by $\beta$-glucuronidase, $\left[{ }^{18} \mathrm{~F}\right]$ fluoroethylamine is released and because it is slowly cleared from tissue demonstrates areas of increased enzyme activity associated with areas of neuroinflammation. While there was not a one-for-one correspondence between R- $\left[{ }^{11} \mathrm{C}\right] \mathrm{PK} 11195$ and $\left[{ }^{18} \mathrm{~F}\right] \mathrm{FEAnGA}$ as had been expected, the investigators demonstrated that there was a relationship between tracer binding and the symptom score which implies that PET imaging was able to more objectively stage the level of neuroinflammation associated with HSV-1 infection and thereby more accurately select cohorts for comparison [85]. Lung inflammation associated with exposure to the pandemic influenza virus (H1N1pdm) [86] and M. tuberculosis [87] was assessed using PET and the glucose analog, $\left[{ }^{18} \mathrm{~F}\right] \mathrm{FDG}$. The investigators correlated the increase in glucose metabolism with viral titers. Like with neuroinflammation, direct measures of the $18-\mathrm{kDa}$ translocator protein or PBR have been performed following a lung lipopolysaccharide challenge utilizing another selective ligand, $N$-benzyl- $N$-methyl-2-[7,8-dihydro-7-(2- ${ }^{18}$ F]fluoroethyl)-8oxo-2-phenyl-9H-purin-9-yl]acetamide ([ $\left.\left.{ }^{18} \mathrm{~F}\right] \mathrm{FEDAC}\right)$ [88] $\left[{ }^{18}\right.$ F]FEDAC binding increased with the severity of lung inflammation and primarily localized to neutrophils and macrophages. A new SPECT tracer, $\left[{ }^{125} \mathrm{I}\right]$ Iodo- $N, N$-diethyl2-]2-(4-methoxy-phenyl)-5,7-dimethyl-pyrazolo[1,5-a] pyrimidin-3-yl]-acetamide ( $\left.\left[{ }^{125} \mathrm{I}\right] \mathrm{DPA} 713\right)$, has been developed and demonstrated to have higher signal-to-noise ratios than R- $\left[{ }^{11} \mathrm{C}\right]$ PK11195 and lower lipophilicity [89, 90]. Measures of tissue hypoxia utilizing $\left[{ }^{64} \mathrm{Cu}\right]$ Copper-diacetylbis $\left(\mathrm{N}^{4}\right.$-methyl-thiosemicarbazone (which is $\left[{ }^{64} \mathrm{Cu}\right] \mathrm{ATSM}$ ) have demonstrated that $M$. tuberculosis-induced tuberculosis lesions in mice are hypoxic and sensitive to varying drug regimens [91]. While these nuclear imaging approaches do not directly measure the degree of infection, they are informative with regards to characterizing the host response to the virus which can be used to identify treatment and potentially new drug discovery approaches.

Evaluation of radiolabeled drugs as tools for nuclear imaging is a new approach to characterizing infection as well as evaluating the pharmacokinetics of the therapeutic. Isoniazid (INH) is routinely used to treat tuberculosis. Utilization of $2-\left[{ }^{18}\right.$ F]fluoroisonicotinic acid hydrazide (2$\left.\left[{ }^{18} \mathrm{~F}\right] \mathrm{INH}\right)$ and evaluation in $M$. tuberculosis-infected animals demonstrated that $2-\left[{ }^{18} \mathrm{~F}\right] \mathrm{INH}$ accumulates in the lung at sites of infection and becomes associated with the mycobacterium such that the radiolabel can be a direct marker of M. tuberculosis [92]. In addition to demonstrating drug exposure and pathogen presence, target-specific compounds amenable to radiolabeling and PET or SPECT imaging can be used to study various processes associated with infection. For example, in a review by Bray and colleagues [93], they hypothesized that radiolabeled compounds can be used to demonstrate that targeted therapeutics bind to the viral envelope glycoprotein, NS3 protease, RNA replication complex, or cell surface E1-E2 protein. Some therapeutic agents exist [93, 94] but little work has been done to radiolabel the molecules and use them as tools to better understand the processes involved in infection and virus/bacteria replication. In addition to small molecules, there are opportunities to radiolabel biologics such as antibodies, mini-bodies, and diabodies as has been demonstrated in the cancer field [95-97]. Based on targeted screening, tools that are more selective for specific viral and bacterial processes could be generated.

\section{Magnetic Resonance Imaging}

A few papers have been published describing the use of MRI in the evaluation of viral and bacterial infections to most notably assess bacterial distribution [97] and germination/ proliferation [98]. S. aureus was labeled with iron oxide nanoparticles which remained on the bacterial surface [97]. The labeling of the bacteria had no effect on growth and ability to infect human umbilical vein endothelial cells in vitro [97]. Upon infection, MRI was able to detect $S$. aureus up to five cycles of cell division and with a minimum detection limit of $10^{5}$ bacteria colony-forming units. In addition, upon macrophage phagocytosis of the labeled bacteria, MRI detected the resulting inflammation associated with infection. Chemical exchange saturation transfer (CEST) MRI, albeit challenging to implement, has recently been used to show that endogenous bacterial contrast can be used to monitor the germination and proliferation of bacteria [98].

Magnetic resonance imaging has also proved useful in evaluating the host response to infection by measuring inflammation [99], brain neurochemical changes [100], and lung pathology [101]. Investigators have employed fluorine19 (F-19) perfluorocarbon emulsions as a means of assessing macrophage infiltration following $S$. aureus infection since the macrophage phagocytosis the F-19 emulsions and F-19 can be detected by MRS [99]. The ${ }^{19} \mathrm{~F}$ MRS signal was detected as early as $48 \mathrm{~h}$ post-infection and out to 9 days post-infection [102]. Mice infected with S. aureus Xen29 containing the optical reporter luxABCDE operon induced a thigh abscess, and following $30 \mathrm{mg} / \mathrm{kg} /$ day vancomycin or $15 \mathrm{mg} / \mathrm{kg} /$ day of linezolid for 7 days, a reduction in both F19 signal by MRS and bioluminescent signal was observed indicating both a decrease in inflammation and infection, respectively [102]. MRS has been applied to simian immunodeficiency virus (SIM)-infected rhesus macaques to study the acute effects of virus on brain neurochemistry, reflective of changes in neuronal health [100]. While the changes noted were brain region specific, focusing on the frontal cortex reductions in $\mathrm{N}$-acetyl aspartate, a measure of neurodegeneration, increases in choline and myoinositol, measures of gliosis, and no change in creatinine and glutamate/glutamine were noted at 2 weeks post-infection 
that resolved by 4 weeks [100]. The changes were highly correlated with the level of viremia and demonstrated that MRS is capable of detecting subtle changes consistent with neurodegeneration/neuroinflammation post-SIM infection. ${ }^{1} \mathrm{H}-\mathrm{MRI}$ and ${ }^{3} \mathrm{He}$ diffusion MRI have proven to be useful tools in evaluating lung architecture following Sendai virus infection [101]. Given that ${ }^{3} \mathrm{He}$ does not diffuse across the alveolar wall, it is very sensitive to defining and quantifying small microstructural changes and combined with ${ }^{1} \mathrm{H}$ MRI establishing that airspace enlargement developed following virus infection [101].

In vivo imaging taken in its entirety has proven to be a sensitive tool for monitoring the distribution of engineered viruses and bacteria by either optical or nuclear imaging approaches and for assessing the consequences of infection. In addition to characterizing disease progression, imaging is a sensitive tool for assessing the degree of viral and bacterial infections relative to plasma titers and for monitoring the effects of drugs on pathogen growth and progression of disease. Despite the amount of work done in the area of optical imaging, opportunities exist to employ nuclear and MRI imaging approaches to perform similar types of studies in non-rodent models and also apply the tools to the development of new drugs by correlating drug distribution and levels with pathogen expression, by linking drug exposure with pharmacologic effect and by establishing predictive preclinical models of drug efficacy that can serve as a surrogate for phase II/III clinical studies given the issues with development of countermeasures for BSL3/4 biothreat agents.

\section{Conclusions}

The pathogenesis of viral and bacterial infections involves pathogen-specific activities such as binding, internalization, replication, muted host anti-viral or anti-bacterial response, and budding and host-specific responses that result in disease. Drug discovery efforts could focus on eliminating the pathogen or on treating or preventing the resulting disease, of which the latter could also have broader application in improving human health. In vivo imaging can be directly applied to better understand the above processes associated with the natural history of infectious agents, the host response, and the discovery and development of drugs for the treatment of infections caused by BSL3 and BSL4 threat agents.

Classical approaches to the study of BSL3/4 infections involve serial necropsies, tissue dissection, plaque counts, and immunohistochemistry to demonstrate the distribution of pathogens and degree of infection, drug extraction from tissues as a measure of drug exposure, and mortality as endpoints for assessing drug efficacy. However, numerous other questions requiring a dynamic assessment of infection and pathophysiology remain unanswered. In addition to knowing that an animal has been exposed to an aerosolized dose of a pathogen, one needs to determine the dose of pathogen received within the lung and the relationship of breathing kinetics to dose. Since distribution of the pathogen in the tissues and organs may differ acutely post-infection versus late in infection, it is important to map the differences so as to insure proper drug exposure late in infection. While the degree of viremia or bacteremia and plasma drug levels may be good measures to demonstrate infection and the potential for drug efficacy, respectively, correlating measures of tissue pathogen and tissue drug concentrations may be more important to link efficacy with drug dose. In some instances like with VEEV, one must know both the time course and route of brain infection and whether the therapeutic agent under development reaches the brain in sufficient quantities to result in a beneficial effect. In all cases noted above, dynamic real-time measurements can provide important data to track infection, host response, and time course for intervention and to assess drug efficacy rather than rely on mortality as the sole endpoint. By using dynamic measures of drug efficacy, one might be better able to discern potential mechanisms for efficacy and potential targets/target organs to refine the drug discovery approach and/or compound.

In summary, in vivo imaging can provide real-time, in-life measures of (1) target distribution and drug exposure, (2) binding of drug to the target, and (3) physiologic or pharmacologic consequences of pathogen or drug intervention. Taken together, in vivo imaging can be used to evaluate countermeasures against BSL3/4 threat agents to answer these three fundamental questions and to develop countermeasures under the U.S. FDA Animal Rule provision with higher confidence of clinical success and benefit.

Acknowledgments. We would like to acknowledge Mr. William F. Discher for his assistance in drawing the two figures and Dr. Jennifer Ojeda for her scientific input into the preparation of Fig. 2. Funding was provided by The Geneva Foundation.

Conflict of Interest. The authors have no conflicts of interest.

Disclaimer. Opinions, interpretations, conclusions, and recommendations stated within the article are those of the authors and are not necessarily endorsed by the U.S. Army.

Open Access This article is distributed under the terms of the Creative Commons Attribution License which permits any use, distribution, and reproduction in any medium, provided the original author(s) and the source are credited.

\section{References}

1. Alderman TS, Frothingham R, Semposki GD (2010) Validation of an animal isolation imaging chamber for use in animal biosafety level-3 containment. Appl Biosaf 15:62-66

2. Davis SL, Nuermberger EL, Um PK et al (2009) Noninvasive pulmonary $\left[{ }^{18} \mathrm{~F}\right]$-2-fluor-deoxy-D-glucose positron emission tomography correlates with bactericidal activity of tuberculosis drug treatment. Antimicrob Agents Chemotherap 53:4879-4884

3. De Kok-Mercado F, Kutlak FM, Jahrling PB (2011) The NIAID integrated research facility at Fort Detrick. Appl Biosaf 16:58-66

4. US Food and Drug Administration (2009) Guidance for industry: animal models - essential elements to address efficacy under the animal rule. http://www.fda.gov/downloads/Drugs/GuidanceComplianceRegulatory Information/Guidances/ucm078923.pdf. Accessed September 7, 2011 \& Updated January 11, 2012 
5. Miranda IA, Cruz-Oliveira C, Da Poian AT (2013) Molecular mechanisms involved in the pathogenesis of alphavirus-induced arthritis. BioMed Res Intl Article ID 973516, 11 pages

6. Steele KE, Twenhafel NA (2010) Review paper: pathology of animal models of alphavirus encephalitis. Vet Pathol 47:790-805

7. Jose J, Snyder JE, Kuhn RJ (2009) A structural and functional perspective of alphavirus replication and assembly. Futur Microbiol 4:837-856

8. Leung JYS, Ng MML, Chu JJH (2011) Replication of alphaviruses: a review on the entry process of alphaviruses into cells. Adv Virol Article ID 249640, 9 pages

9. Fernandez I, Volonte L, Risco C (2013) Virus factories: biogenesis and structural design. Cell Microbiol 15:24-34

10. Weaver SC, Winegar R, Manger ID et al (2012) Alphaviruses: population genetics and determinants of emergence. Antiviral Res 94:242-257

11. Adler NRL, Govan B, Cullinane M et al (2009) The molecular and cellular basis of pathogenesis in melioidosis: how does Burkholderia pseudomallei cause disease? FEMS Microbiol Rev 33:1079-1099

12. Galyov EE, Brett PJ, DeShazer D (2010) Molecular insights into Burkholderia pseudomallei and Burkholderia mallei pathogenesis. Annu Rev Microbiol 64:495-517

13. Pudla M, Limposuwan K, Utaisincharoen P (2011) Burkholderia pseudomallei-induced expression of a negative regulator, sterile- $\alpha$ and Armadillo motif-containing protein, in mouse macrophages: a possible mechanism for suppression of the MYD88-independent pathway. Infect Immun 79:2921-2927

14. Wong DF, Tauscher J, Grunder G (2009) The role of imaging in proof of concept for CNS drug discovery and development. Neuropsychopharm Rev 34:187-203

15. Lee C-M, Farde L (2006) Using positron emission tomography to facilitate CNS drug development. Trends Pharmacol Sci 27:310-316

16. Cole PE, Schwarz AJ, Schmidt ME (2012) Applications of imaging biomarkers in the early clinical development of central nervous system therapeutic agents. Clin Pharmacol Ther 91:315-320

17. Zhang L, Villalobos A, Beck EM et al (2013) Design and selection parameters to accelerate the discovery of novel central nervous system positron emission tomography (PET) ligands and their application in the development of a novel phosphodiesterase 2A PET ligand. J Med Chem $56: 4568-4579$

18. Choi SR, Golding G, Zhuang Z et al (2009) Preclinical properties of ${ }^{18}$ F-AV-45: a PET agent for Abeta plaques in the brain. J Nucl Med 50:1887-1894

19. Poisnei G, Dhilly M, Moustie O et al (2012) PET imaging with $\left[{ }^{18} \mathrm{~F}\right] \mathrm{AV}-45$ in an APP/PS1-21 murine model of amyloid plaque deposition. Neurobiol Aging 33:2561-2571

20. Wong DF, Rosenber PB, Zhou Y et al (2010) In vivo imaging of amyloid deposition in Alzheimer disease using the radioligand ${ }^{18} \mathrm{~F}-\mathrm{AV}$ 45 (florbetapir $\mathrm{F}^{18}$ ). J Nucl Med 51:913-920

21. Yang D, Xie Z, Stephenson D et al (2011) Volumetric MRI and MRS provide sensitive measures of Alzheimer's disease neuropathology in inducible Tau transgenic mice ( $\mathrm{rTg} 4510)$. Neuroimage $54: 2652-2658$

22. Kantarci K, Jack CR, Xu YC et al (2000) Regional metabolic patterns in mild cognitive impairment and Alzheimer's disease: a ${ }^{1} \mathrm{H}$ MRS study. Neurol 55:210-217

23. O'Farrell AC, Shnyder SD, Marston G et al (2013) Non-invasive molecular imaging for preclinical cancer therapeutic development. Br J Pharm 169:719-735

24. Zhang CC, Zhengming Y, Li W et al (2011) $\left[{ }^{18}\right.$ F]FLT-PET imaging does not always "light up" proliferating tumor cells. Clin Cancer Res 18:1303-1312

25. Zhang CC, Yan Z, Zhang Q et al (2010) PF-03732010: a fully human monoclonal antibody against p-cadherin with antitumor and antimetastatic activity. Clin Cancer Res 16:5177-5188

26. Taniguchi Y, Kawano K, Minowa T et al (2010) Enhanced antitumor efficacy of folate-linked liposomal doxorubicin with TGF-beta type I receptor inhibitor. Cancer Sci 10:2207-2213

27. Wu AM, Yazaki PJ, Tsai SW et al (2000) High-resolution microPET imaging of carcinoembryonic antigen-positive xenografts by using a copper ${ }^{64}$-labeled engineered antibody fragment. Proc Natl Acad Sci U S A 97:8495-8500

28. Tawakoi A, Migrina RQ, Hoffman U et al (2005) Noninvasive in vivo measurement of vascular inflammation with $\mathrm{F}^{18}$ fluorodeoxyglucose positron emission tomography. J Nucl Cardiol 12:294-301
29. Rudd JHF, Myer KS, Bansilal S et al (2007) ${ }^{18}$ Flurodeoxyglucose positron emission tomography imaging of atherosclerotic plaque inflammation is highly reproducible: implications for atherosclerosis therapy trials. J Am Coll Cardiol 50:892-896

30. Tahara N, Kai H, Ishibashi M et al (2006) Simvastatin attenuates plaque inflammation: evaluation by fluordeoxyglucose positron emission tomography. J Am Coll Cardiol 48:1825-1831

31. Singhal T, Ding YS, Weinzimmer D et al (2011) Pancreatic beta cell mass PET imaging and quantification with $\left[{ }^{11} \mathrm{C}\right] \mathrm{DTBZ}$ and $\left[{ }^{18} \mathrm{~F}\right]-(+)-$ DTBZ in rodent models of diabetes. Mol Imaging Biol 13:973-984

32. Normandin MD, Petersen KF, Ding YS et al (2012) In vivo imaging of endogenous pancreatic beta cell mass in healthy and type 1 diabetic subjects using $\left[{ }^{18} \mathrm{~F}\right]-(+)-\mathrm{DTBZ}$ and PET. J Nucl Med 53:908-916

33. Beckers C, Ribbens C, Andre B et al (2004) Assessment of disease activity in rheumatoid arthritis with ${ }^{18}$ F-FDG PET. J Nucl Med 45:956-964

34. Dorward DA, Lucas CD, Rossi AG et al (2012) Imaging inflammation: Molecular strategies to visualize key components of the inflammatory cascade, from initiation to resolution. Pharm Therap 135:182-199

35. Zhang Y, Kundu B, Fairchild KD et al (2007) Synthesis of novel neutrophil-specific imaging agents for positron emission tomography (PET) imaging. Bioorg Med Chem Lett 17:6876-6878

36. Zhang J, Zhang S, Guo H et al (2010) Synthesis and biological evaluation of a novel ${ }^{99 \mathrm{~m}} \mathrm{TC}(\mathrm{CO}) 3$ complex of ciprofloxacin dithiocarbamate as a potential agent to target infection. Bioor Med Chem Lett 20:3781-3784

37. Locke LW, Chordia MD, Zhang Y et al (2009) A novel neutrophilspecific PET imaging agent: cFLFLFK-PEG- ${ }^{64} \mathrm{Cu}$. J Nucl Med 50:790-797

38. Yagle KJ, Eary JF, Tait JF et al (2005) Evaluation of ${ }^{18} \mathrm{~F}$-annexin V as a PET imaging agent in an animal model of apoptosis. J Nucl Med 46:658-666

39. Brader P, Serganova I, Blasberg RG (2013) Noninvasive molecular imaging using reporter genes. J Nucl Med 54:167-172

40. Sander WE, Metzger ME, Morizono K et al (2006) Noninvasive molecular imaging to detect transgene expression of lentiviral vector in nonhuman primates. J Nucl Med 47:1212-1219

41. Yaghoubi SS, Berger F, Gambhir SS (2007) Studying the biodistribution of positron emission tomography reporter probes in mice. Nat Protoc 2(7):1752-1755

42. Tjuvajev JG, Finn R, Watanabe K et al (1996) Noninvasive imaging of herpes virus thymidine kinase gene transfer and expression: a potential method for monitoring clinical gene therapy. Cancer Res 56:4087-4095

43. Ponomarev V, Doubrovin M, Shavrin A et al (2007) A human-derived reporter gene for noninvasive imaging in humans: mitochondrial thymidine kinase type 2. J Nucl Med 48:819-826

44. Campbell DO, Yaghoubi SS, Su Y et al (2012) Structure-guided engineering of human thymidine kinase 2 as a positron emission tomography reporter gene for enhanced phosphorylation of non-natural thymidine analog reporter probe. J Biol Chem 287:446-454

45. Deroose CM, Chitneni SK, Gijsbers R et al (2012) Preliminary validation of varicella zoster virus thymidine kinase as a novel reporter gene for PET. Nucl Med Biol 39:1266-1274

46. Haberkorn U (2001) Gene therapy with sodium/iodide symporter in hepatocarcinoma. Exp Clin Endocrinol Diabetes 109:60-62

47. Haddad D, Chen NG, Zhang Q et al (2011) Insertion of the human sodium iodide symporter to facilitate deep tissue imaging does not alter oncolytic or replication capability of a novel vaccinia virus. J Transl Med 9:1-14

48. Pennheiter AR, Russell SJ, Carlson SK (2012) The sodium iodide symporter (NIS) as an imaging reporter for gene, viral, and cell-based therapies. Curr Gene Ther 12:33-47

49. Altmann A, Kissel M, Zitzmann S et al (2003) Increased MIBG uptake after transfer of the human norepinephrine transporter gene in rat hepatoma. J Nucl Med 44:973-980

50. Rogers BE, Zinn KR, Buchsbaum DJ (2000) Gene transfer strategies for improving radiolabeled peptide imaging and therapy. Q J Nucl Med 44:208-223

51. Liang Q, Satyamurthy N, Barrio JR et al (2001) Noninvasive, quantitative imaging in living animals of a mutant dopamine D2 receptor reporter gene in which ligand binding is uncoupled from signal transduction. Gene Ther 8:1490-1498

52. Moroz MA, Serganova I, Zanzonico P et al (2007) Imaging hNET reporter gene expression with ${ }^{124}$ I-MIBG. J Nucl Med 48:827-836

53. Lee SW, Lee SH, Biswal S (2012) Magnetic resonance reporter gene imaging. Theranostics 2:403-412 
54. Gilad AA, Winnard PT Jr, van Zijl PC et al (2007) Developing MR reporter genes: promises and pitfalls. NMR Biomed 20:275-290

55. Milho R, Smith CM, Marques $\mathrm{S}$ et al (2009) In vivo imaging of murid herpesvirus-4 infection. J Gen Virol 90:21-32

56. Oliver SL, Zaerboni L, Sommer M et al (2008) Development of recombinant varicella-zoster viruses expressing luciferase fusion proteins for live in vivo imaging in human skin and dorsal root ganglia xenografts. J Virol Meth 154:182-193

57. Patterson M, Poussard A, Taylor K et al (2011) Rapid, non-invasive imaging of alphaviral brain infection: reducing animal numbers and morbidity to identify efficacy of potential vaccines and antivirals. Vaccine 29:9345-9351

58. Ziegler SA, Nuckois J, McGee CE et al (2011) In vivo imaging of Chikungunya virus in mice and Aedes mosquitoes using Renilla luciferase clone. Vector Borne Zoonotic Dis 11:1471-1477

59. Goff A, Twenhafel N, Garrison A et al (2007) In vivo imaging of cidofovir treatment of cowpox virus infection. Virus Res 128:88-98

60. Yamada S, Kosugi I, Katano $\mathrm{H}$ et al (2010) In vivo imaging assay for the convenient evaluation of antiviral compounds against cytomegalovirus in mice. Antiviral Res 88:45-52

61. Cho JS, Zussman J, Donegan NP et al (2011) Noninvasive in vivo imaging to evaluate immune responses and antimicrobial therapy against Staphyloccocus aureus and USA300 MRSA skin infections. J Invest Dermatol 131:907-915

62. Rhee KJ, Cheng H, Harris A et al (2011) Determination of spatial and temporal colonization of enteropathogenic E. coli and enterohemorrhagic $E$. coli in mice using bioluminescent in vivo imaging. Gut Microbes 2:34-41

63. Glomski IJ, Piris-Gimenez A, Huerre M et al (2007) Primary involvement of pharynx and Peyer's patch in inhalation and intestinal anthrax. PLoS Pathog 3:699-708

64. Sun Y, Connor MG, Pennington JM et al (2012) Development of bioluminescent bioreporters for in vitro and in vivo tracking of Yersinia pestis. PLoS One 7(10):e47123. doi:10.1371/journal.pone.0047123

65. Nham T, Filali S, Danne C et al (2012) Imaging of bubonic plague dynamics by in vivo tracking of bioluminescent Yersinia pestis. PLoS One 7(4):e34714. doi:10.1371/journal.pone.0034714

66. Sha J, Rosenzweig JA, Kirtley ML et al (2013) A non-invasive in vivo imaging system to study dissemination of bioluminescent Yersina pestis CO92 in a mouse model of pneumonic plague. Micro Pathog 55:39-50

67. Bina XR, Miller MA, Bina JE (2010) Construction of a bioluminescence reporter plasmid for Francisella tularensis. Plasmid 64:156-161

68. Massey S, Johnston K, Mott TM et al (2011) In vivo bioluminescence imaging of Burkholderia mallei respiratory infection and treatment in the mouse model. Front Microbiol 2:1-10

69. Owen SJ, Batzloff M, Chehrehasa F et al (2009) Nasal-associated lymphoid tissue and olfactory epithelium as portals of entry for Burkholderia pseudomallei in murine melioidosis. J Infect Dis 199:1761-1770

70. Niska JA, Shahbazian JH, Ramos RI et al (2013) Vancomycin-rifampin combination therapy has enhanced efficacy against an experimental Staphylococcus aureus prosthetic joint infection. Antimicrob Agents Chemotherap 57(10):5080-5086

71. Andreu N, Zelmer A, Sampson SL et al (2013) Rapid in vivo assessment of drug efficacy against Mycobacterium tuberculosis using an improved firefly luciferase. J Antimicrob Chemotherap 68:2118-2127

72. Kong Y, Yao H, Ren $\mathrm{H}$ et al (2010) Imaging tuberculosis with endogenous $\beta$-lactamase reporter enzyme fluorescence in live mice. Proc Natl Acad Sci U S A 107(27):12239-12244

73. Ning W, Lee $S$, Wang $Z$ et al (2011) Matodextrin-based imaging probes detect bacteria in vivo with high sensitivity and specificity. Nat Mater 10(8):602-607

74. Hernandez FJ, Huang L, Olson ME et al (2014) Noninvasive imaging of Staphylococcus aureus infections with a nuclease-activated probe. Nat Med 20(3):301-306

75. Perin F, Laurence D, Savary I et al (1997) Radioactive technetium ${ }^{99 m}$ labeling of Salmonella abortusovis for the assessment of bacterial dissemination in sheep by in vivo imaging. Vet Microb 51:171-180

76. Plotkowski MC, Beck G, Bernardo-Filho M et al (1987) Evaluation of the ${ }^{99 m}$ technetium labeling effect on Pseudomonas aeruginosa surface properties. Ann Inst Pasteur Microbiol 138:415-426

77. Bernardo-Filho M, Pereira JA, Boasquevisque EM et al (1991) Technetium $^{99 \mathrm{~m}}$ distribution into Klebsiella pneumonia. J Nucl Biol Med 35:152-166
78. Arden WA, Yacko MA, Jay M et al (1993) Scintigraphic evaluation of bacterial translocation during hemorrhagic shock. J Surg Res 54:102-106

79. Thakur ML (1987) Live bacteria labeled with ${ }^{111}$ In. Eur J Nucl Med $13: 266$

80. Aziz SM, Sandefer EP, Pauly TH et al (1993) Comparative disposition kinetics of ${ }^{111}$ In labeled group $B$ Streptococcus and neutrophils during onset of sepsis-induced pulmonary hypertension. Biol Neonate 63:86-95

81. Ardehali R, Mohammad SF (1993) ${ }^{111}$ Indium labeling of microorganisms to facilitate the investigation of bacterial adhesion. J Biomed Mat Res 27:269-275

82. Bettegowda C, Foss CA, Cheong I et al (2005) Imaging bacterial infections with radiolabeled 1-(2'-deoxy-2'-fluoro- $\beta$-D-arabinofuranosyl)-5iodouracil. Proc Natl Acad Sci U S A 102:1145-1150

83. Pullambhatia M, Tessier J, Beck G et al (2012) $\left[^{125}\right.$ I]FIAU imaging in a preclinical model of lung infection: quantification of bacterial load. Am J Nucl Med Mol Imaging 2:260-270

84. Davis SL, Be NA, Lamichhane G et al (2009) Bacterial thymidine kinase as a non-invasive imaging reporter for Mycobacterium tuberculosis in live animals. PLoS One 4(7):e6297. doi:10.1371/journal.pone.0006297

85. Antunes IF, Doorduin J, Haisma HJ, et al. (2102) ${ }^{18}$ F-FEAnGA for PET of $\beta$-glucoronidase activity in neuroinflammation. J Nucl Med 53:451-458

86. Jonsson CB, Camp JV, Wu A et al (2012) Molecular imaging reveals a progressive pulmonary inflammation in lower airways in ferrets infected with 2009 H1N1 pandemic influenza virus. PLoS One 7(7):e40094. doi:10.1371/journal.pone.0040094

87. Davis SL, Nuermberger EL, Um PK et al (2009) Noninvasive pulmonary $\left[{ }^{18} \mathrm{~F}\right]$-2-fluoro-deoxy-D-glucose positron emission tomography correlates with bactericidal activity of tuberculosis drug treatment. Antimicrob Agents Chemotherp 53:4879-4884

88. Hatori A, Yui J, Yamasaki T et al (2012) PET imaging of lung inflammation with $\left[{ }^{18} \mathrm{~F}\right] \mathrm{FEDAC}$, a radioligand for translocator protein (18 kDa). PLoS One 7(9):e45065. doi:10.1371/journal.pone.0045065

89. Wang H, Pullambhatla M, Guilarte TR et al (2009) Synthesis of $\left[{ }^{125}\right.$ I]IodoDPA-713, a new probe for inflammation. Biochem Biophys Res Commun 389:80-83

90. Foss CA, Harper JS, Wand H et al (2013) Noninvasive molecular imaging of tuberculosis-associated inflammation with radioiodinated DPA-713. J Infect Dis 208:2067-2074

91. Harper J, Skerry C, Davis SL (2012) Mouse model of necrotic tuberculosis granulomas develops hypoxic lesions. J Infect Dis 205:593-602

92. Weinstein EA, Liu L, Ordonoze AA et al (2012) Noninvasive determination of $2-\left[{ }^{18} \mathrm{~F}\right]$-fluoroisonicotinic acid hydrazide pharmacokinetics by positron emission tomography in Mycobacterium tuberculosis-infected mice. Antimicrob Agents Chemother 56:6284-6290

93. Bray M, Di Mascio M, de Kok-Mercado F et al (2010) Radiolabeled antiviral drugs and antibodies as virus-specific imaging probes. Antiviral Res 88:129-142

94. Liu L, Xu Y, Shea C et al (2010) Radiosynthesis and bioimaging of the tuberculosis chemotherapeutics isoniazid, rifampicin and pyrazinamide in baboons. J Med Chem 53:2882-2891

95. McCabe KE, Wu AM (2010) Positive progress in immunoPET-not just a coincidence. Cancer Biother Radiopharm 25:253-261

96. Van Dongen GAMS, Poot AJ, Vugts DJ (2012) PET imaging with radiolabeled antibodies and tyrosine kinase inhibitors: immunoPET and TK1-PET. Tumor Biol 33:607-615

97. Hoerr V, Tuchscherr L, Huve J et al (2013) Bacteria tracking by in vivo magnetic resonance imaging. BMC Biol 11:1-13

98. Liu G, Bettegowda C, Qiao Y et al (2013) Noninvasive imaging of infection after treatment with tumor-homing bacteria using Chemical Exchange Saturation Transfer (CEST) MRI. Magn Reson Med 70:1690-1698

99. Hertlein T, Sturm V, Jakob $P$ et al $(2013){ }^{19} \mathrm{~F}$ magnetic resonance imaging of perfluorocarbons for the evaluation of response to antibiotic therapy in a Staphylococcus aureus infection model. PLoS One 8(5):e64440. doi:10.1371/journal.pone.0064440

100. Ratai EM, Pilkenton SJ, Greco JB et al (2009) In vivo proton magnetic resonance spectroscopy reveals region specific metabolic responses to SIV infection in the macaque brain. BMC Neurosci 10:1-12

101. Wang W, Nguyen NM, Agapov E et al (2012) Monitoring in vivo changes in lung microstructure with ${ }^{3} \mathrm{He}$ MRI in Sendai virus-infected mice. J Appl Physiol 112:1593-1599

102. Hertlein T, Sturm V, Kircher S et al (2011) Visualization of abscess formation in a murine thigh infection model of Staphylococcus aureus by ${ }^{19} \mathrm{~F}$-magnetic resonance imaging (MRI). PLoS One Mar 24:6(3):e18246 